\title{
Magnetic Particles Weight as an Indicator for Heavy Metals Concentration
}

\author{
Sajjad Abbasi $1,2, * \mathbb{D}$ \\ 1 Department of Earth Sciences, College of Science, Shiraz University, Shiraz 71454, Iran \\ 2 Department of Radiochemistry and Environmental Chemistry, Institute of Chemical Sciences, Faculty of Chemistry, Maria \\ Curie-Sklodowska University, 3 Maria Curie-Sklodowska Square, 20-031 Lublin, Poland \\ Correspondence: sajjad.abbasi@shirazu.ac.ir; sajjad.abbasi.h@gmail.com;
}

Scopus Author ID 57203061256

Received: 25.06.2021; Revised: 18.08.2021; Accepted: 22.08.2021; Published: 11.09.2021

\begin{abstract}
Due to the ever-increasing population growth, urbanization and industrial activity are essential for meeting the basic needs of households. Together with the resulting traffic load and ineffective waste disposal, these factors are the most important sources of environmental pollution in this century. Therefore, the concentration of contaminants should be regularly monitored to protect ecological and human health. The common analytical methods are time-consuming, expensive, and account for a potential source of contamination. In this study, Spearman correlation coefficient, cluster analysis, PMF model, and spatial analysis indicated that anthropogenic magnetic particle weight (MPW) indicates the heavy metal load originated from anthropogenic activity. Hence, it is introduced as a simple, rapid, and cost-effective method for monitoring heavy metal contamination in soil, dust together with bed and suspended sediment. Whenever limited background knowledge prevents planning a comprehensive environmental investigation, this method can be used as the first step for gaining a general insight towards the present status and organize ranked set sampling design.
\end{abstract}

Keywords: magnetic particles weight; heavy metal; anthropogenic activity; pollution; contamination; monitoring; nanoparticle; microparticle.

(c) 2021 by the authors. This article is an open-access article distributed under the terms and conditions of the Creative Commons Attribution (CC BY) license (https://creativecommons.org/licenses/by/4.0/).

\section{Introduction}

Environmental magnetism is an interdisciplinary field with a wide range of applications. The regulating environmental processes in mineral assemblages [1], size and shape of minerals [2], along with magnitude, source, scale, and temporal evolution of anthropogenic pollution [3], were studied by this method. During fossil fuel combustion and steel production, magnetic spherules are clearly distinguishable from their natural counterparts $[4,5]$. Magnetic minerals may also serve as carriers of pollutants. Therefore, it is critical to consider them for determining pollution degree in the environment.

The common analytical methods (for example, ICP-MS, GC-MS, ICP-OES, and AAS) are invasive, expensive, time-consuming, and a likely source of pollution [3, 6-8]. However, magnetic methods can be useful for the rapid and cost-effective detection of pollutants and a specific range of hazardous airborne particles. Management of magnetic emissions depends on epidemiological and toxicological data, environmental statistics, and regional information systems. Local authorities should implement effective policies aimed at minimizing the impact of pollution. In the current study, a simple method will be introduced for rapid, inexpensive, and accurate monitoring of heavy metal pollution. 


\section{Materials and Methods}

\subsection{Sampling and analyses.}

In Bushehr city, south Iran, a total of 30 street dust, soil, and background samples were collected under the stable weather conditions of the dry season to represent various forms of land use and possible sources of contamination (e.g., industrial, commercial, traffic-related and residential). Samples were collected adjacent to road curbs. In a 5-m radius of the sampling points, approximately $500 \mathrm{~g}$ of dust were gathered using a plastic taper and brush and then transported to the laboratory in an airtight polyethylene container. To obtain the background value, five soil samples (including some subsamples) were also taken at $>40 \mathrm{~cm}$ depth (Figures 1 and 2) in the areas not affected by anthropogenic activity. The samples were analyzed for heavy metals (see [9]). Note that analyzed samples for heavy metals and magnetic weight were from the same samples.

Eight water and sediment samples (S1 to S8) were also obtained from Khoshk River, south Iran (Figure 1). To discover the changes in water and sediment chemistry downstream, the first sampling site (S1) on the Khoshk River was chosen. S2 to S7 are situated in a stretch of the river, passing through the urban area. Municipal and household sewage affects all stations, except for S1, S2, and S8. The last sampling site (S8) is located near small farms and the Maharlu saline Lake. The local background sediment and water samples (R1 and R2) were collected upstream. The concentrations of heavy metals were reported by Salati and Moore [10]. Worth mentioning that heavy metals concentration and their sources in the Khoshk river are similar each year, and the result of the current study is just ready to introduce a new method. Similar results were indicated in our previous research [3].

To investigate the magnetic characteristics of street dust and background soil, $100 \mathrm{~g}$ $(<2 \mathrm{~mm})$ of the sample was treated in the laboratory according to one of the following steps: 1) Evenly spread the air-dried sample on a clean surface and pass a paper-wrapped magnet over the sample to collect the magnetic particles. It was repeated until no magnetic particle remained in the sample. 2) $100 \mathrm{ml}$ of distilled water was added to the sample to disperse the particles in a beaker, and a magnet was then attached to the wall of the beaker to attract the magnetic particles while stirring the water. These procedures were repeated for sediments, except for the case that $500 \mathrm{~g}$ samples were used. Each sample's separated magnetic particles were weighted using an electronic analytical microbalance (Model LIBROR AEL-40SM; SHIMADZU Co., Kyoto, Japan) with a $1 \mu \mathrm{g}$ sensitivity.

The magnetic particles in water were also collected by putting a plastic-wrapped magnet in river water for 7 days, and the adsorbed magnetic particles in each station were weighted as described above.

\subsection{Geologic and mineralogic settings of the study areas.}

Alluvium and quaternary deposits are the major geological formations around Bushehr city where calcite (61.2\%), dolomite (15.6\%), quartz (6.5\%), magnetite (4\%) are dominant [9].

Tectonically, Shiraz is a part of the Zagros Fold-Thrust Belt and located in an NW-SE elongated syncline bounded by Derak and Babakouhi anticlines in the west and east, respectively. Geologically, the major lithological formations were formed between Cretaceous and Quaternary in the area, which includes Sachun (red gypseous marls with gypsum beds and local development of chalky, fine dolomitic limestones and sandy pebble beds), Asmary- 
Jahrom (thin-bedded low weathering limestones and grey marlstones, and well-bedded fossiliferous marly limestones), Razak (predominantly red and some green marls with interbedded red sandstones, grey limestones and occasionally gypsum beds, and thin limestones), Aghajari (interbedded buff to red sandstones, pebbly sandstones, and silty marls and marlstones), Bakhtiari (massive and well-bedded conglomerates with occasional sandstone and siltstone layers and lenses), alluvials and recent deposits. The results of X-ray diffractometry indicated that the dominant minerals are calcite $(55.13 \%)$, dolomite $(19.65 \%)$, and quartz (10.3\%), and minor minerals include gypsum, albite, muscovite, chlorite, cristobalite, chlorapatite, and hematite [11].

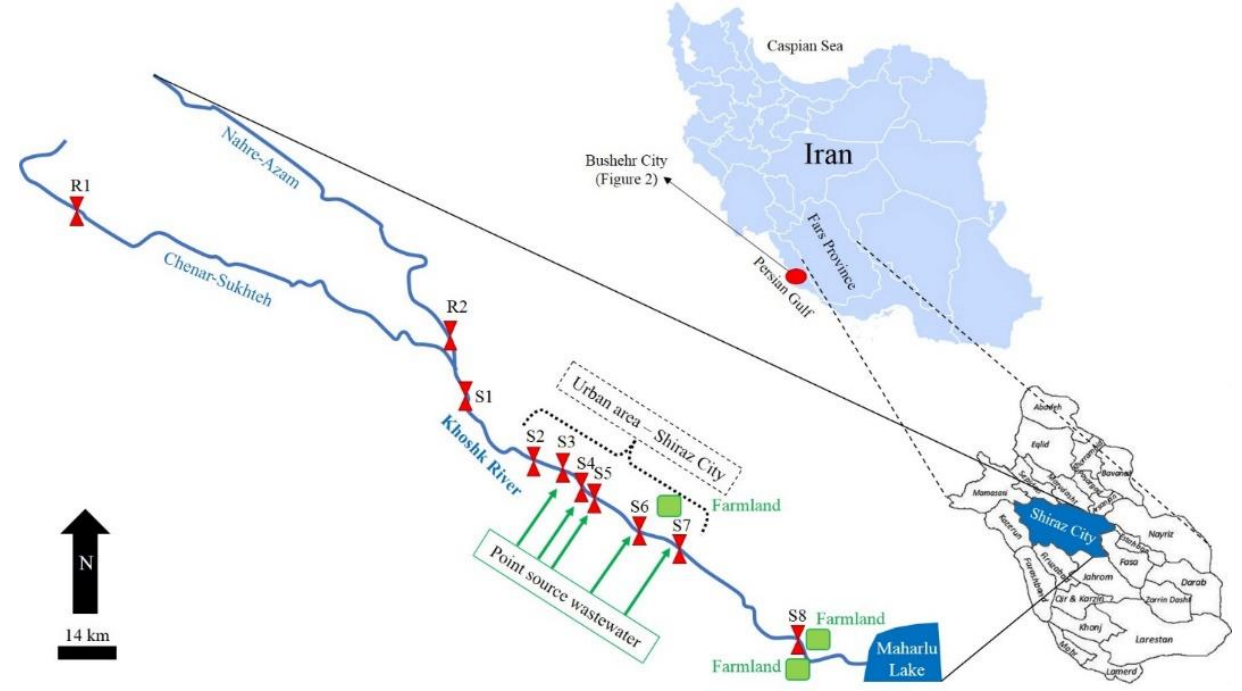

Figure 1. Bed and suspended sediment sampling points in Khoshk River (Shiraz). Street dust and soil sampling points (Bushehr, the red circle) are illustrated in Figure 2.

\subsection{Statistical methods.}

Descriptive statistics, correlation coefficient, and cluster analyses (CA) were applied using SPSS version 19.0 software. The positive matrix factorization (PMF) modeling was also employed by the US-EPA PMF 5.0 software (USEPA 2014) to determine the sources and contribution of the heavy metals and magnetic particles. Abbasi et al. [12] and Lv [13] described the calculation of uncertainty and rotation tools in detail. PMF model was bootstrapped with 100 runs, a least correlation $\mathrm{R}$-value $=0.6$, and seed $=$ random. Three to six agents were examined, and the optimal number of agents was determined based on the slope of the $\mathrm{Q}$ value versus the number of agents. From the 20 runs, the convergent run with minimum Qrobust reported was used for the solutions in this article. In statistics, the MAD is a robust measure of the variability of a univariate sample of quantitative data used for background calculating [14].

\subsection{Quality control ( $Q C)$ and quality assurance $(Q A)$.}

For heavy metal analysis in street dust, blank samples, standard reference materials (OREAS45EA), and analytical double copies were performed to check QC/QA. Recovery percentages demonstrated good agreement between the measured and the certified values. Moreover, in each medium (i.e., soil, dust, sediment, and water), three duplicate samples were weighted, and the results of magnetic particles weight (MPW) were almost similar. 


\section{Results and Discussion}

Table 1 indicates descriptive statistics of MPW in the street dust along with bed and suspended sediment. According to Abbasi et al. [9], concentrations of $\mathrm{Pb}, \mathrm{As}, \mathrm{Cd}, \mathrm{Cr}, \mathrm{Hg}, \mathrm{Cu}$, $\mathrm{Zn}, \mathrm{Ni}, \mathrm{Sb}$, and Mo in Bushehr street dust were more than the corresponding values in the world soils [15]. Maximum levels of $\mathrm{Zn}, \mathrm{Cu}, \mathrm{As}, \mathrm{Mo}$, and $\mathrm{Sb}$ in $\mathrm{S} 14$ stations can be attributed to the heavy traffic loads and oil refineries in north Bushehr [16- 18]. Concentrations of $\mathrm{Pb}$ (S14>S1>S11>S12>S17>S18) are controlled by vehicular traffic. , The enrichment factor of heavy metals indicates a higher contamination load in the northern part of the town because of elevated traffic emissions and greater population [9], which leads to the occurrence of magnetic particles in the samples (Figure 2).

Table 1. Statistical summary of MPW in street dust, sediment, suspended sediment (water) samples.

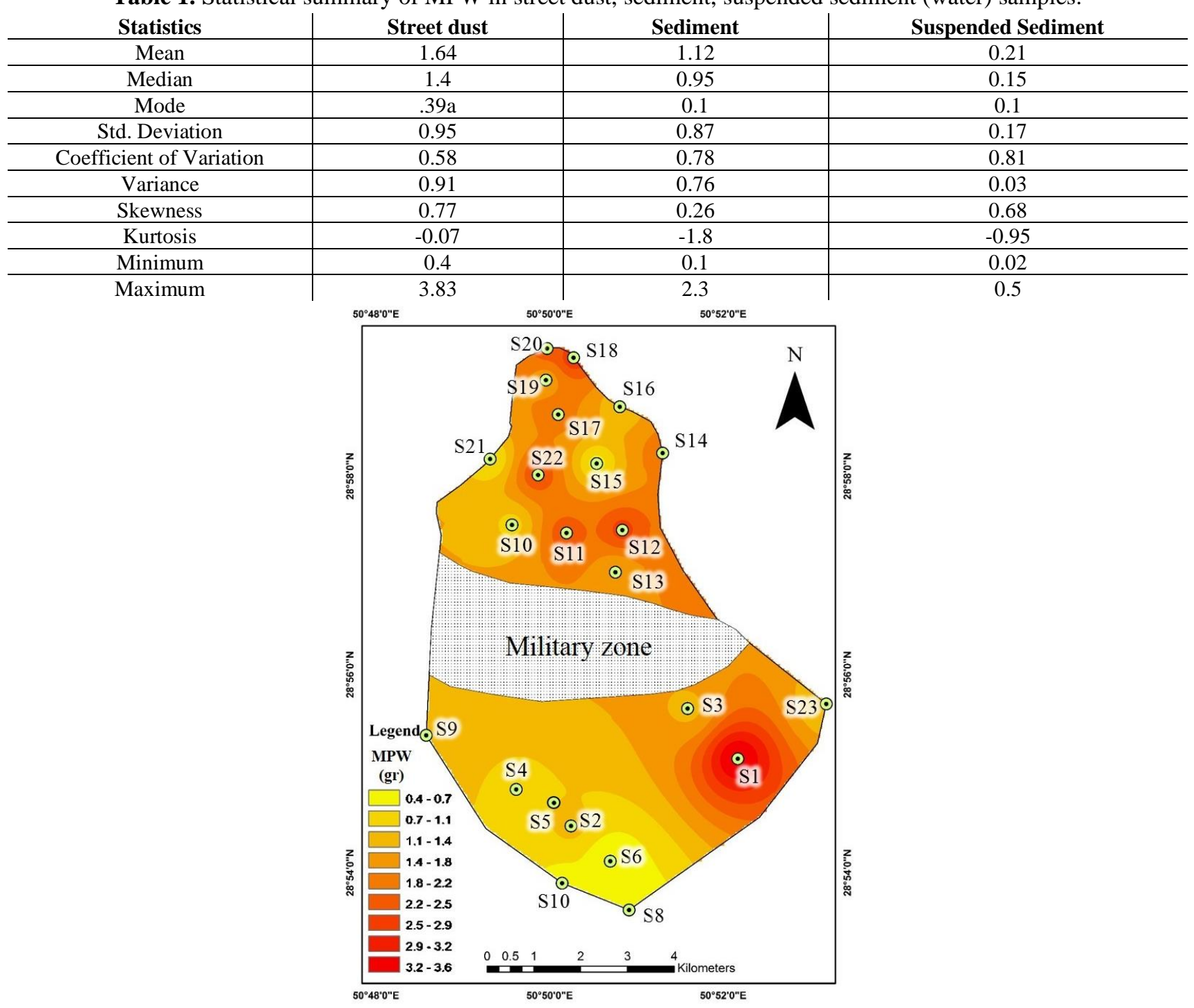

Figure 2. Spatial distribution of MPW in street dust of Bushehr.

Similarly, higher MPW was observed in the sediment and water of Khoshk River enriched in heavy metals (Figure 3), especially in S2 to S7 stations that were influenced by urban wastewater discharge [10]. Heavy metal concentration and MPW generally increase from upstream to downstream. The values are lower in the background samples (soil in Bushehr and bed and suspended sediment in Khoshk River). 


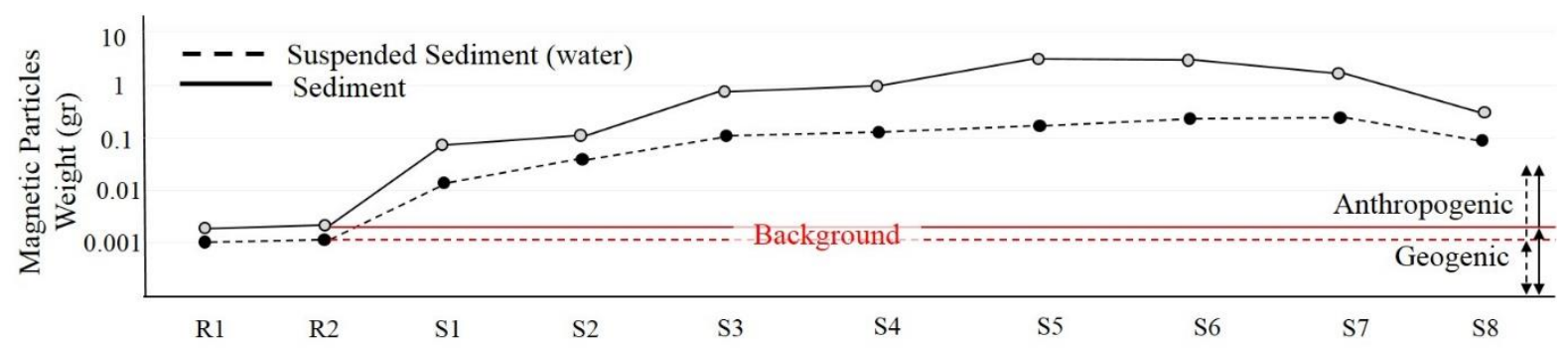

Figure 3. MPW in bed and suspended sediment and variation of mean heavy metals concentrations (mg/l) in water and sediment of Khosh River (Shiraz) collected in 2005 and 2007 [10].

Standard deviation, skewness, and Shapiro-Wilk test displayed that the data are nonnormally distributed. Therefore, non-parametric analyses were carried out. The Spearman correlation coefficient analysis indicated that MPW has a strong positive correlation with $\mathrm{Zn}$, $\mathrm{As}, \mathrm{Pb}, \mathrm{Mo}, \mathrm{Mn}, \mathrm{Fe}, \mathrm{Cu}, \mathrm{Cd}, \mathrm{V}$, and $\mathrm{Sb}$ elements (Table 2). In street dust, $\mathrm{As}, \mathrm{Cu}, \mathrm{Mo}, \mathrm{Sb}, \mathrm{Pb}$, $\mathrm{V}$, and $\mathrm{Zn}$ can be attributed to vehicular traffic and combustion of burning fossil fuels, while $\mathrm{Al}, \mathrm{Cr}, \mathrm{Co}, \mathrm{Sc}, \mathrm{Ni}$, and Ti originate mainly from geogenic sources [9]. The meaningful correlation between $\mathrm{Fe}$ and MPW is probably indicative of $\mathrm{Fe}$ in magnetic particles. Based on the coefficient of variation (CV), the elements can be classified into two groups: (1) Ti, Ni, Fe, $\mathrm{Cr}, \mathrm{Co}, \mathrm{Mn}, \mathrm{Cd}$, and $\mathrm{Al}$, with $\mathrm{CV}<0.4$; and (2) the rest with $\mathrm{CV}>0.4$. Contrary to the elements with natural origins, the anthropogenic elements have higher CV [14, 19]. To provide further evidence, one sample of separated magnetic particles analyzed and high concentrations of $\mathrm{Zn}$, $\mathrm{Cu}, \mathrm{Pb}, \mathrm{Mo}, \mathrm{Sb}, \mathrm{Cr}, \mathrm{Mn}$, and $\mathrm{Fe}$ (3488 mg kg-1, $2554 \mathrm{mg} \mathrm{kg}{ }^{-1}, 325 \mathrm{mg} \mathrm{kg}^{-1}, 511.9 \mathrm{mg} \mathrm{kg}^{-1}$, $>0.01 \%, 1730 \mathrm{mg} \mathrm{kg}^{-1}, 1927 \mathrm{mg} \mathrm{kg}^{-1}$, and >10\%, respectively) and usual $\mathrm{Al}$ and Sc contents $\left(12,208\right.$ and $2.9 \mathrm{mg} \mathrm{kg}^{-1}$, respectively) were obtained. Therefore, magnetic particles probably originate from anthropogenic sources.

Table 2. Spearman correlation coefficient between MPW and heavy metals.

\begin{tabular}{|c|c|}
\hline Elements & MPW \\
\hline Mo & $.597 * *$ \\
\hline $\mathrm{Cu}$ & $.517 * *$ \\
\hline $\mathbf{P b}$ & $.614 * *$ \\
\hline $\mathbf{Z n}$ & $.599 * *$ \\
\hline $\mathrm{Ni}$ & 0.334 \\
\hline $\mathrm{Co}$ & 0.223 \\
\hline Mn & $.456 *$ \\
\hline $\mathbf{F e}$ & $.853 * *$ \\
\hline As & $.421 *$ \\
\hline Cd & $.658 * *$ \\
\hline Sb & $.530 * *$ \\
\hline $\mathbf{V}$ & $.525 * *$ \\
\hline $\mathrm{Cr}$ & 0.396 \\
\hline $\mathrm{Ti}$ & 0.299 \\
\hline $\mathrm{Sc}$ & 0.1 \\
\hline $\mathrm{Hg}$ & 0.06 \\
\hline $\mathrm{Al}$ & 0.014 \\
\hline
\end{tabular}

The source of heavy metals and magnetic particles was also investigated by CA and PMF models. First, the CA was carried out with the wards method and standardized by the standard deviation (Figure 4). The results showed that MPW has stronger correlations with anthropogenic elements (i.e., $\mathrm{Cu}, \mathrm{Sb}, \mathrm{Zn}, \mathrm{As}, \mathrm{Mo}, \mathrm{Hg}, \mathrm{V}$, and $\mathrm{Pb}$ ) and weaker correlations with $\mathrm{Fe}, \mathrm{Cr}$, and $\mathrm{Cd}$. The MPW does not indicate a statistically meaningful relationship with Sc, Mn, 
$\mathrm{Ni}, \mathrm{Co}, \mathrm{Al}$, and $\mathrm{Ti}$. Then, some new parameters were added to PMF to find the contribution of MPW in anthropogenic and geogenic sources. Malm and Hand [20] investigated the physical and optical properties of aerosols in the IMPROVE program and, based on their finding, some parameters can be considered geogenic sources. In this study, organic matter, calcium carbonate, and unmeasured mass (UnM) were considered indicators of the geogenic source. To reach mass closure on samples, the UnM was calculated by subtracting the reconstructed mass, which was developed based on the background knowledge about the likely forms of various elements (e.g., $\mathrm{Al}_{2} \mathrm{O}_{3}$ for $\mathrm{Al}, \mathrm{SiO}_{2}$ for $\mathrm{Si}, \mathrm{TiO}_{2}$ for $\mathrm{Ti}, \mathrm{CaO}$ for $\mathrm{Ca}$, along with $\mathrm{FeO}$ and $\mathrm{Fe}_{2} \mathrm{O}_{3}$ for $\mathrm{Fe}$ ), from the measured mass. The calculated UnM values represent the compounds that were not measured like organic matter mass. Different formulas can be considered for UnM depending on the media. In this study, the following formulas were applied for UnM calculation:

Street dust or sediment or suspended sediment particles $=$

Soil + Particulate Organic Matter + Sea Salt

Soil $=2.2[\mathrm{Al}]+2.49[\mathrm{Si}]+1.94[\mathrm{Ti}]+1.63[\mathrm{Ca}]+2.42[\mathrm{Fe}]$

Particulate Organic Matter $=1.4$ [Organic Carbon]

Sea Salt $=1.8\left[\mathrm{Cl}^{-}\right]$

In the formulas mentioned above, it is assumed that: (1) the coarse and fine grains of soil is mainly composed of oxides of $\mathrm{Al}, \mathrm{Ca}, \mathrm{Si}, \mathrm{Mg}, \mathrm{Fe}$, and $\mathrm{Ti}$, with other trace elements [21]; (2) equal proportions of $\mathrm{FeO}$ and $\mathrm{Fe}_{2} \mathrm{O}_{3}$ (the two common oxides of iron) occur; (3) the factor of 2.42 for iron also includes the mass of $\mathrm{K}_{2} \mathrm{O}$ in soil, based on the $(\mathrm{K} / \mathrm{Fe})=0.6$ ratio for sedimentary soils [22].

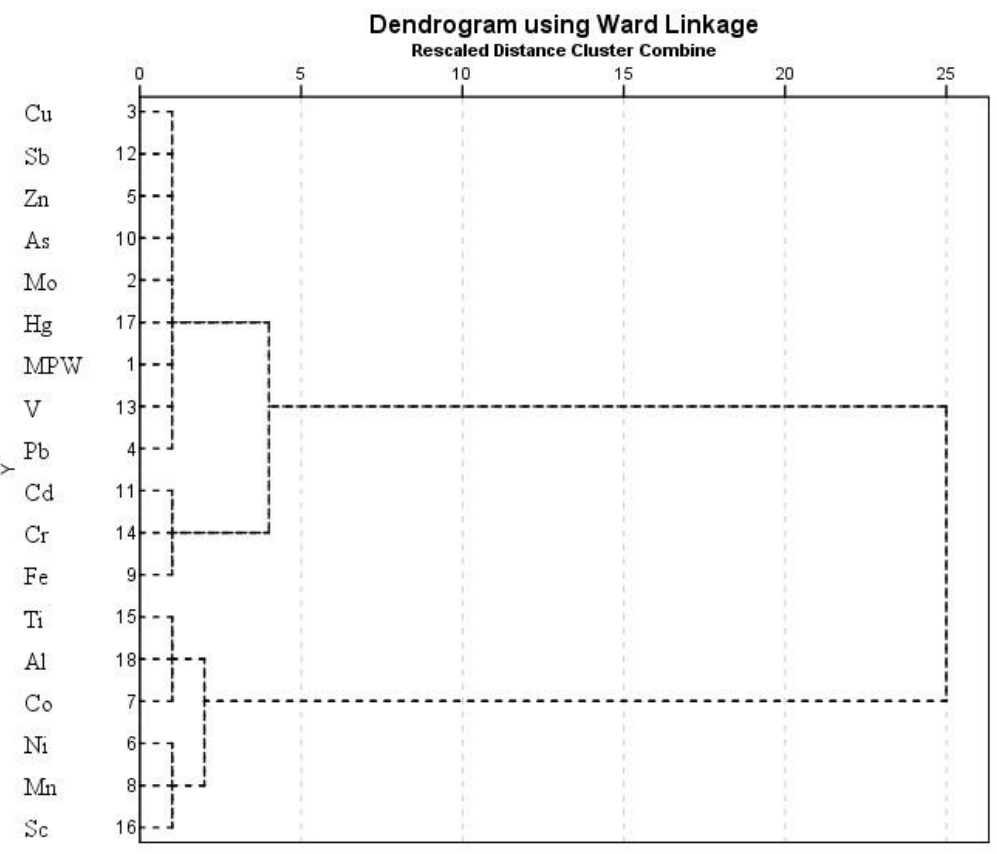

Figure 4. Hierarchical dendrogram for MPW and heavy metals.

PMF model was then run based on UnM, MPW, and heavy metals (Figures 5 and 6). The result indicated that MPW, $\mathrm{Mo}, \mathrm{Cu}, \mathrm{Pb}, \mathrm{Zn}, \mathrm{Sb}$, and $\mathrm{Hg}$ have similar behavior and indicate the highest contribution. MPW shows a medium contribution with $\mathrm{Fe}, \mathrm{As}, \mathrm{Mn}, \mathrm{V}, \mathrm{Cr}, \mathrm{Ti}$, and the lowest with the rest of the elements. Of the elements with the lowest contribution with MPW, the geogenic elements (such as $\mathrm{Al}, \mathrm{Sc}, \mathrm{Cr}, \mathrm{Co}$, and $\mathrm{Ni}$ ) and $\mathrm{UnM}$ have a strong 
correlation and high contribution. According to MPW and UnM contributions in the first and second factors (Figure 5 and 6), the contribution of MPW with anthropogenic and geogenic elements is approximately 80 and $20 \%$, respectively. Therefore, MPW is affected by both anthropogenic and geogenic magnetic particles. Some magnetic minerals such as ilmenite, pyrrhotite, jacobite, goethite, magnetite, and hematite are naturally present in the environment and can adsorb on the magnet. Some of these minerals may also originate from non-geogenic sources. Therefore, collecting background samples facilitates calculating the anthropogenic MPW using the following formula:

Anthropogenic MPWi $=$ MPWi - Background MPW

where I refers to each sample and, for instance, background MPW in the street dust (Bushehr), bed sediment, and suspended sediment (Shiraz) samples were 0.00121, 0.001, and 0.0009 gr, respectively (Figure 3). According to the results of the present article, anthropogenic MPW is an acceptable parameter for effective monitoring of environmental pollution in different mediums such as dust, soil, and sediment.

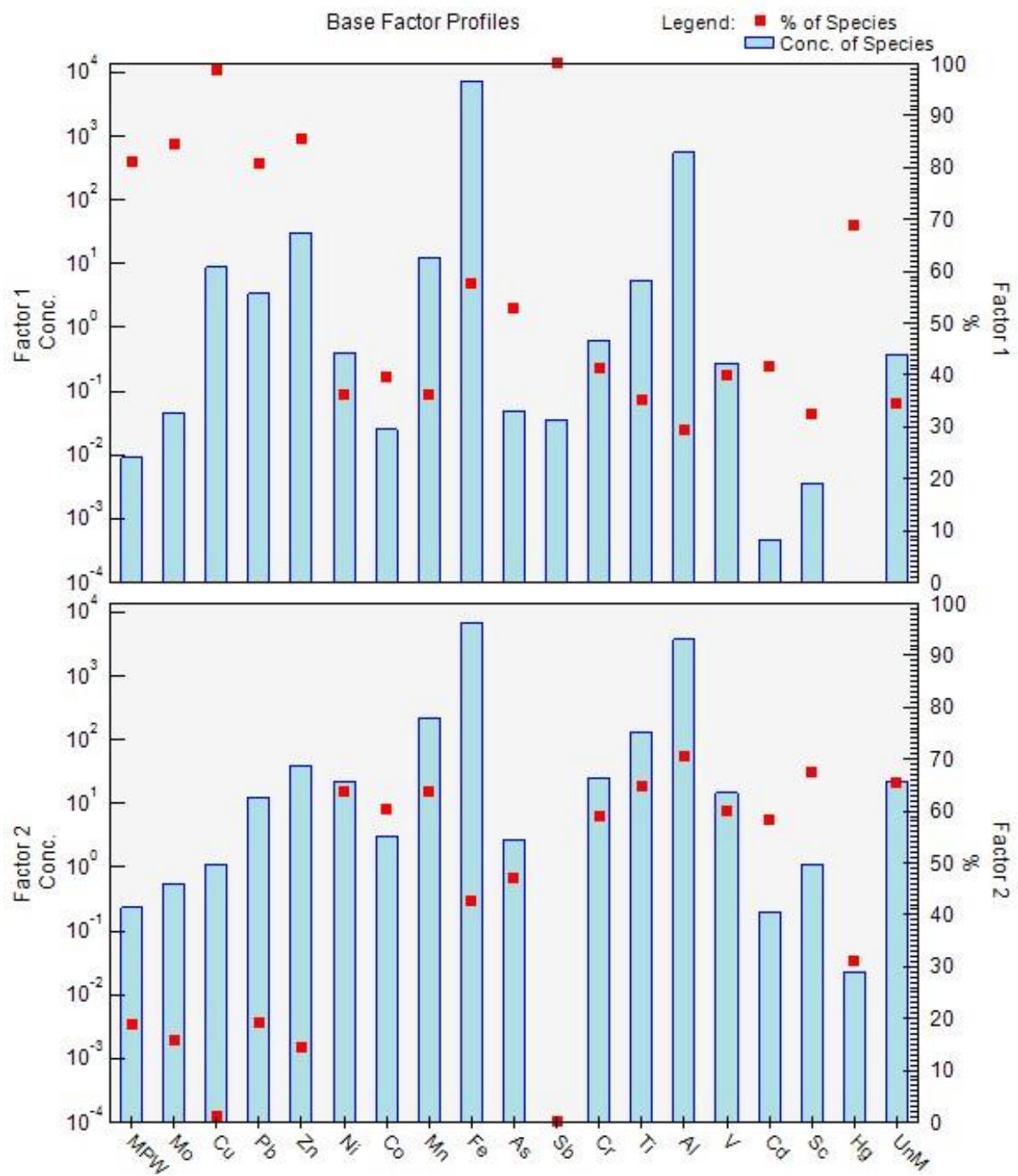

Figure 5. A stacked graph of PMF models for heavy metals and MPW based on IMPROVE program. 


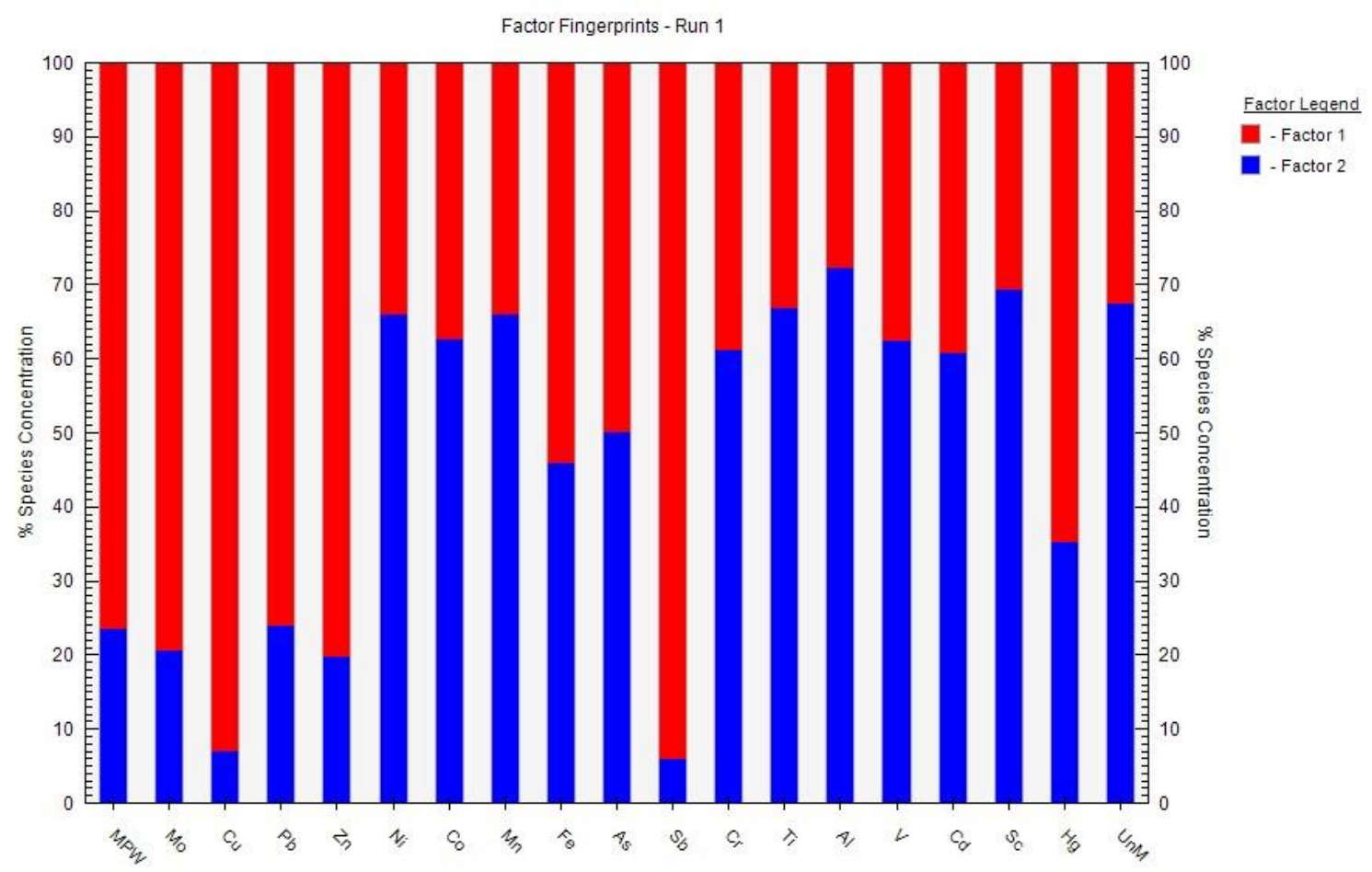

Figure 6. A stacked graph showing the fingerprint of the identified elemental and MPW sources.

\section{Conclusions}

The spatial distribution of MPW and enrichment factor of heavy metals was similar, revealing more magnetic particles in the polluted stations. The Spearman correlation coefficient and CA showed that MPW has a strong correlation with anthropogenic elements. Based on UnM, MPW, and concentrations of heavy metals, the PMF model indicated similar behavior of MPW, Mo, $\mathrm{Cu}, \mathrm{Pb}, \mathrm{Zn}, \mathrm{Sb}$, and $\mathrm{Hg}$, representing the highest contribution. However, MPW shows a medium contribution with Fe, As, Mn, V, Cr, and Ti and the lowest contribution with the rest of the elements. Thus, the following results can be obtained from PMF model (i) the same sources (such as automobiles, abrasion of car parts, brake pads, car tires, burning fossil fuels, industrial activities) simultaneously release the elements and magnetic particles; (ii) magnetic particles adsorb $\mathrm{Mo}, \mathrm{Cu}, \mathrm{Pb}, \mathrm{Zn}, \mathrm{Sb}, \mathrm{Hg}$; (iii) heavy metals are in the magnetic particles' structures; (iv) a combination of the factors mentioned above.

In the present study, MPW was affected by both anthropogenic and geogenic magnetic particles, leading to the contribution of MPW to anthropogenic and geogenic elements by approximately 80 and 20\%, respectively. Therefore, the anthropogenic MPW can be calculated by subtracting background MPW from MPWi (i.e., Anthropogenic MPWi = MPWi Background MPW).

\section{Funding}

This research was funded by Shiraz University, grant number 99GRC1M371631.

\section{Acknowledgments}

The author wishes to express his gratitude to Shiraz University for supporting. 


\section{Conflicts of Interest}

\section{The authors declare no conflict of interest.}

\section{References}

1. Liu, Q.; Roberts, A.P.; Larrasoaña, J.C.; Banerjee; S.K.; Guyodo, Y.; Tauxe, L; Oldfield, F. Environmental magnetism: principles and applications. Reviews of Geophysics 2012, 4, https://doi.org/10.1029/2012RG000393.

2. Shaterabadi, Z.; Nabiyouni, G.; Soleymani, M. Correlation between effects of the particle size and magnetic field strength on the magnetic hyperthermia efficiency of dextran-coated magnetite nanoparticles. Materials Science and Engineering: C 2020, 117, https://doi.org/10.1016/j.msec.2020.111274.

3. Abbasi, S.; Keshavarzi, B.; Moore, F.; Hopke, P.K.; Kelly, F.J; Dominguez, A.O. Elemental and magnetic analyses, source identification, and oxidative potential of airborne, passive, and street dust particles in Asaluyeh County, Iran. Science of The Total Environment 2020, 707, https://doi.org/10.1016/j.scitotenv.2019.136132.

4. Maity, R.; Venkateshwarlu, M.; Mondal, S.; Kapawar, M.R.; Gain, D.; Paul, P. Magnetic and microscopic characterization of anthropogenically produced magnetic particles: a proxy for environmental pollution. International Journal of Environmental Science and Technology 2020, 16, 1-16, https://doi.org/10.1007/s13762-020-02902-x.

5. Basavaiah, N.; Blaha, U.; Das, P.K.; Deenadayalan, K.; Sadashiv, M.B; Schulz, H. Evaluation of environmental magnetic pollution screening in soils of basaltic origin: results from Nashik Thermal Power Station, Maharashtra, India. Environmental Science and Pollution Research 2012, 19, 3028-3038, https://doi.org/10.1007/s11356-012-0816-1.

6. Jones, S.; Richardson, N.; Bennett, M.; Hoon, S.R. The application of magnetic measurements for the characterization of atmospheric particulate pollution within the airport environment. Science of the Total Environment 2015, 502, 385-390, https://doi.org/10.1016/j.scitotenv.2014.09.010.

7. Hofman, J.; Stokkaer, I.; Snauwaert, L.; Samson, R. Spatial distribution assessment of particulate matter in an urban street canyon using biomagnetic leaf monitoring of tree crown deposited particles. Environmental Pollution 2013, 183, 123-132, https://doi.org/10.1016/j.envpol.2012.09.015.

8. Narayana, A.C.; Ismaiel, M.; Priju, C.P. An environmental magnetic record of heavy metal pollution in Vembanad lagoon, southwest coast of India. Marine Pollution Bulletin, 2021, 167, https://doi.org/10.1016/j.marpolbul.2021.112344.

9. Abbasi, S.; Keshavarzi, B.; Moore, F.; Delshab, H.; Soltani, N.; Sorooshian, A. Investigation of microrubbers, microplastics and heavy metals in street dust: a study in Bushehr city, Iran. Environmental earth sciences 2017, 76, 1-19, https://doi.org/10.1007/s12665-017-7137-0.

10. Salati, S.; Moore, F. Assessment of heavy metal concentration in the Khoshk River water and sediment, Shiraz, Southwest Iran. Environmental monitoring and assessment 2010, 164, 677-689, https://doi.org/10.1007/s10661-009-0920-y.

11. Keshavarzi, B.; Tazarvi, Z.; Rajabzadeh, M.A.; Najmeddin, A. Chemical speciation, human health risk assessment and pollution level of selected heavy metals in urban street dust of Shiraz, Iran. Atmospheric Environment 2015, 119, 1-10, https://doi.org/10.1016/j.atmosenv.2015.08.001.

12. Abbasi, S.; Rezaei, M.; Keshavarzi, B.; Mina, M., Ritsema, C.; Geissen, V. Investigation of the 2018 Shiraz dust event: Potential sources of metals, rare earth elements, and radionuclides; health assessment. Chemosphere 2021, 279, https://doi.org/10.1016/j.chemosphere.2021.130533.

13. Lv, J. Multivariate receptor models and robust geostatistics to estimate source apportionment of heavy metals in soils. Environmental pollution 2019, 244, 72-83, https://doi.org/10.1016/j.envpol.2018.09.147.

14. Abbasi, S.; Keshavarzi, B.; Moore, F.; Mahmoudi, M.R. Fractionation, source identification and risk assessment of potentially toxic elements in street dust of the most important center for petrochemical products, Asaluyeh County, Iran. Environmental earth sciences 2018, 77, 1-19, https://doi.org/10.1007/s12665-018-7854-z.

15. Kabata-Pendias, A. Soil-plant transfer of trace elements—an environmental issue. Geoderma 2004, 122, 143 149, https://doi.org/10.1016/j.geoderma.2004.01.004.

16. Donado, E.P.; Oliveira, M.L.; Gonçalves, J.O.; Dotto, G.L.; Silva, L.F. Soil contamination in Colombian playgrounds: effects of vehicles, construction, and traffic. Environmental Science and Pollution Research 2021, 28, 166-176, https://doi.org/10.1007/s11356-020-09965-w.

17. Malakootian, M.; Mohammadi, A.; Nasiri, A.; Asadi, A.M.S.; Conti, G.O.; Faraji, M. Spatial distribution and correlations among elements in smaller than $75 \mu \mathrm{m}$ street dust: ecological and probabilistic health risk assessment. Environmental Geochemistry and Health 2021, 43, 567-583, https://doi.org/10.1007/s10653020-00694-0.

18. Naraki, H.; Keshavarzi, B.; Zarei, M.; Moore, F.; Abbasi, S.; Kelly, F.J.; Dominguez, A.O.; Jaafarzadeh, N. Urban street dust in the Middle East oldest oil refinery zone: Oxidative potential, source apportionment rand 
health risk assessment of potentially toxic elements. Chemosphere 2021, 268, https://doi.org/10.1016/j.chemosphere.2020.128825.

19. Huang, J.; Wu, Y.; Sun, J.; Li, X.; Geng, X.; Zhao, M.; Sun, T.; Fan, Z. Health risk assessment of heavy metal (loid) $\mathrm{s}$ in park soils of the largest megacity in China by using Monte Carlo simulation coupled with Positive matrix factorization model. Journal of Hazardous Materials 2021, 415, https://doi.org/10.1016/j.jhazmat.2021.125629.

20. Malm, W.C.; Hand, J.L. An examination of the physical and optical properties of aerosols collected in the IMPROVE program. Atmospheric Environment 2007, 41, 3407-3427, https://doi.org/10.1016/j.atmosenv.2006.12.012.

21. Malm, W.C.; Sisler, J.F.; Huffman, D.; Eldred, R.A.; Cahill, T.A. Spatial and seasonal trends in particle concentration and optical extinction in the United States. Journal of Geophysical Research: Atmospheres 1994, 99, 1347-1370, https://doi.org/10.1029/93JD02916.

22. Begum, B.A.; Biswas, S.K.; Hopke, P.K.; Cohen, D.D. Multi-element analysis and characterization of atmospheric particulate pollution in Dhaka. Aerosol and Air Quality Research 2006, 6, 334-359, https://doi.org/10.4209/aaqr.2006.12.0001. 